\title{
COMPORTAMENTO INDIVIDUAL, CULTURA E MUDANÇA SOCIAL*
}

INDIVIDUAL BEHAVIOR, CULTURE, AND SOCIAL CHANGE

SIGRID S. GLENN ${ }^{1}$

\author{
UNIVERSITY OF NORTH TEXAS, UNITED STATES OF AMERICA
}

\section{RESUMO}

O princípio da seleção operante é examinado como um modelo para a seleção cultural e o papel do ambiente social é sugerido como o elemento crítico na emergência de fenômenos culturais. Contingências operantes são comparadas com contingências de seleção cultural, denominadas metacontingências. Esses dois tipos de relações de contingência resultam em linhagens de recorrências que evoluem e que podem tornar-se cada vez mais complexas em termos do número e da organização de seus elementos. Além do papel nas contingências comportamentais entrelaçadas recorrentes que constituem a organização cultural, o comportamento operante desempenha outro papel nas culturas. Apesar dos operantes dos indivíduos serem funcionalmente independentes uns dos outros, o comportamento de cada pessoa pode contribuir para um efeito cumulativo relevante para o bem-estar de muitas pessoas. Similarmente, os produtos de metacontingências também podem contribuir para um efeito cumulativo. A relação entre linhagens operantes que evoluem independentemente, ou entre linhagens culturais que evoluem independentemente, e seu efeito cumulativo, é identificada como uma macrocontingência. Macrocontingências não envolvem seleção cultural per se. Uma engenharia cultural efetiva requer a identificação de macrocontingências que produzem efeitos indesejáveis e a alteração de contingências operantes ou metacontingências relevantes de modo a produzir mudanças nos efeitos cumulativos.

Palavras-chave: contingências operantes, macrocontingências, metacontingências, seleção cultural, seleção operante.

\section{ABSTRACT}

The principle of operant selection is examined as a prototype of cultural selection, and the role of the social environment is suggested as the critical element in the emergence of cultural phenomena. Operant contingencies are compared to cultural selection contingencies, designated as metacontingencies. Both of these types of contingency relations result in evolving lineages of recurrences that can become increasingly complex in the number and organization of their elements. In addition to its role in the recurring interlocking behavioral contingencies that constitute cultural organization, operant behavior plays another role in cultures. Although the operants of individuals are functionally independent of one another, the behavior of each person may contribute to a cumulative effect that is relevant to the wellbeing of many people. Similarly, the outcomes of metacontingencies may also contribute to a cumulative effect. The relation between independently evolving operant lineages, or between independently evolving cultural lineages, and their cumulative effect is identified as a macrocontingency. Macrocontingencies do not involve cultural-level selection per se. Effective cultural engineering requires identifying the macrocontingencies that produce less than desirable effects and altering the relevant operant contingencies or metacontingencies to produce change in the cumulative effects.

Key words: operant contingencies, macrocontingencies, metacontingencies, cultural selection, operant selection.

*Artigo originalmente publicado em inglês como: Glenn, Sigrid S. (2004). Individual behavior, culture, and social change. The Behavior Analyst, 27 (2), 133-151 (@) Association for Behavior Analysis International, 2004). Traduzido por Natália S. Marques, Angelo A. S. Sampaio e Felipe L. Leite. Os tradutores agradecem a Henrique V. B. R. Angelo pelos comentários e sugestões a respeito de versões prévias dessa tradução. Revisão da tradução de Marcelo Benvenuti. 
Comportamento aprendido é a subestrutura das culturas humanas e a transmissão do comportamento aprendido potencializa a evolução das culturas humanas. O comportamento humano produz mudanças cumulativas nos ambientes humanos, e ambientes em mudança contínua demandam ajustes comportamentais constantes. Ajustes bem sucedidos podem se tornar parte de práticas culturais e serem transmitidos para as próximas gerações.

Culturas cada vez mais complexas surgiram da interação entre a capacidade humana para aprender, as contingências de reforço que explicam o comportamento aprendido dos indivíduos e a transmissão cultural do comportamento aprendido tudo no contexto formador das características físicas dos ambientes locais. Em um período de pouco mais de 10.000 anos, as culturas humanas evoluíram de pequenos bandos de caçadores-coletores, que supostamente mostravam uns aos outros como produzir fogo e ferramentas simples, a enormes Estados-nação nos quais as atividades integradas de centenas de pessoas participam na produção do tecido usado na confecção da roupa vendida como Marca X ou na criação de leis de acordo com as quais milhões de pessoas vivem. Décadas de educação, formal e informal, são agora exigidas para desenvolver e manter os repertórios comportamentais necessários que participam das vastas redes de comportamento humano interrelacionado que constituem a cultura moderna. ${ }^{2}$

A maioria das características das culturas modernas não foi planejada. Ao contrário, elas simplesmente surgiram como resultado das contingências de seleção que fortaleceram o comportamento dos indivíduos (cf. Johnson, 2001). O planejamento sistemático parece surgir quando práticas culturais produzem resultados imprevistos, indesejados, ou reconhecidos tardiamente como tendo resultados abaixo do ideal. Resultados do comportamento humano em curso, não intencionais e prejudiciais à cultura são primeiro identificados, então lamentados e, às vezes, finalmente, enfrentados. Mas eles podem ser enfrentados de modo suficientemente rápido para garantir a sobrevivência?

Há quase 20 anos, B. F. Skinner (1987) questionou por que não estávamos agindo para salvar o mundo. Sua resposta foi que as práticas culturais da espécie humana em geral não incluíam o comportamento verbal necessário para analisar de modo apropriado os problemas e planejar as mudanças ambientais necessárias para promover a sobrevivência da cultura (e possivelmente da própria espécie). A prática cultural verbal que estava ausente, conforme sugerido por Skinner, era a linguagem da Análise Experimental do Comportamento - especificamente, a prática de analisar as contingências de reforço que mantém o comportamento dos membros de uma cultura e predizem resultados para quando essas contingências são alteradas. Ele ainda sugeriu que a análise experimental do comportamento daria suporte a uma teoria da evolução cultural do mesmo modo que a teoria da evolução biológica de Darwin teve suporte na ciência experimental da genética.

A analogia de Skinner (1987) oferece um ponto de partida para explorar neste artigo pelo menos um modo de usar a linguagem da Análise Experimental do Comportamento como base para uma interpretação teórica da cultura. Embora o interesse final de Skinner fosse promover mudanças que melhorassem as vidas das pessoas, o ponto do seu artigo era que o caminho para a ação efetiva começa com práticas verbais eficazes. Em 2004, no centésimo aniversário de seu nascimento, a humanidade precisa mais do que nunca de uma linguagem que ajude na análise de seus problemas de um modo que leve à ação efetiva.

Nas seções seguintes, eu reviso o princípio da seleção operante e o papel do ambiente social humano nas contingências comportamentais. Defino, então, cultura e práticas culturais e considero o papel do comportamento operante nelas. Duas relações na cultura - macrocontingências e metacontingências são distinguidas e o papel das contingências comportamentais em cada tipo de relação é explicado como um prelúdio para possibilidades de mudança social. Finalmente, retorno às propostas de Skinner sobre a relação entre as práticas verbais da análise experimental do comportamento e a interpretação teórica da cultura.

\section{O PRINCÍPIO DA SELEÇÃO OPERANTE}

Os princípios comportamentais descrevem relações entre comportamento e ambiente que explicam a aquisição e manutenção do comportamento aprendido. O princípio da seleção operante é o alicerce sobre o qual outros princípios comportamentais se sustentam. Como outros princípios científicos, sua forma simples mascara a complexidade do universo que ele descreve. O princípio da seleção operante é às vezes formulado como "o comportamento é uma função de suas consequências". Uma afirmação tão trivial não explicita os diferentes papéis desempenhados pelo tempo no processo de seleção descrito pelo princípio. A afirmação também obscurece o fato de que as palavras comportamento e suas, as quais parecem se referir à mesma coisa, efetivamente se referem a coisas distintas. Vamos explorar essa afirmação de modo a descrever de modo similar a seleção cultural. A Figura 1 é uma representação esquemática da seleção operante ocorrendo ao longo do tempo. ${ }^{3}$

$\mathrm{O}$ esquema mostra, primeiro, que o universo no qual a seleção comportamental ocorre engloba ações e eventos externos a essas ações (ambiente) de um organismo único (uma criança aprendendo a empilhar blocos, digamos). Obviamente, não nos interessaríamos por esse universo se a seleção operante afetasse apenas o comportamento desse organismo. De fato, o processo apareceu cedo o bastante na história evolutiva na Terra para anteceder os seres humanos por milhões de anos e, portanto, é uma característica comportamental compartilhada por muitas espécies, talvez de modo mais significativo pelos humanos. 


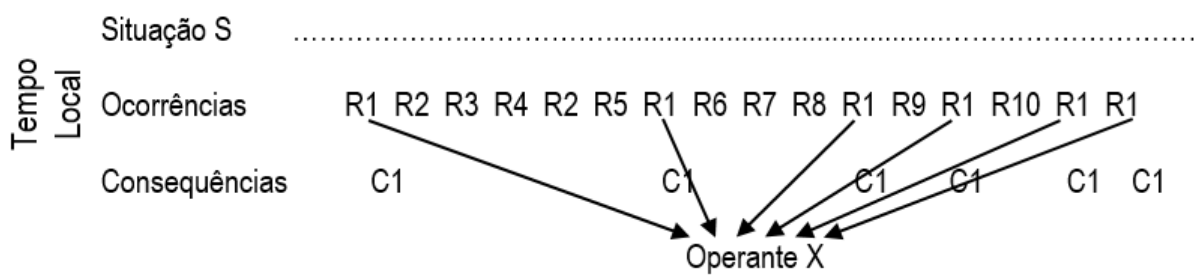

Ambiente

Comportamento

Ambiente

Figura 1. Recorrências de R1 ocorrendo com frequência crescente como resultado de contingência operante.

No esquema, três tipos de eventos são representados ocorrendo uns em relação aos outros em um dado período de tempo. Um tipo de evento compreende as ações da Pessoa $\mathrm{P}$, cujas respostas são designadas pela letra $\mathrm{R}$ seguida por um número. Cada $\mathrm{R}$ numerado é uma forma diferente de manipular um bloco. Para tornar o exemplo o mais simples possível, todas as Rs ocorrem durante um período de um minuto em uma Situação $S$ estável, presente a cada ocorrência de R (os blocos estão em uma superfície plana e tudo no quarto de recreação permanece constante). Na situação, as ações que um observador identifica como R1 (e.g., colocar um bloco exatamente em cima de outro) são confiavelmente seguidas por um tipo particular de mudança de estímulo, C1 (uma torre aparece). Essa consequência não se segue a outras ações ocorrendo na Situação S. A Situação $\mathrm{S}$ e as consequências representadas por $\mathrm{C} 1$ são variáveis ambientais.

Os arranjos temporais locais a cada ocorrência de R1 e a subsequente C1 na Situação S são mostrados pelos arranjos diagonais das letras. A relação temporal recorrente entre instâncias de R1 (mas não de outras Rs) e $\mathrm{C} 1$ é tipicamente designada como uma contingência de dois termos. $\mathrm{O}$ comportamento identificado como $\mathrm{R} 1$ é mostrado ocorrendo várias vezes. Apenas um outro comportamento ocorre mais de uma vez (R2), e ele ocorre apenas duas vezes. No período de $1 \mathrm{~min}$ de observação, R1 pode ser vista ocorrendo com uma frequência crescente e, ao final do minuto, R1 predomina no fluxo comportamental da Pessoa P.

Assuma que R1 ocorresse raramente antes, se ocorresse, no fluxo comportamental da Pessoa P. O esquema representa a aquisição de um operante que rotulamos de Operante $\mathrm{X}$ (nesse caso, um operante de "empilhar blocos"). A relação temporal confiável de R1 e C1 (juntamente com a ausência de tal relação temporal entre outras Rs e C1) é a contingência que causa um aumento na frequência com que R1 ocorre no fluxo comportamental da Pessoa $\mathrm{P}$ em um ambiente estável.

Recorde o princípio "o comportamento é uma função de suas consequências." O comportamento particular que é uma função das consequências nesse exemplo é o Operante $\mathrm{X}$ (uma linhagem de respostas R1). O que é seguido por alguma consequência são ocorrências de R1 (cada resposta de empilhar). A relação temporal (e geralmente causal) entre ocorrências de R1 e ocorrências de C1 gerou uma linhagem de R1 que rotulamos de X. Tanto a linhagem (o operante empilhar blocos da criança) quanto as respostas individuais (cada instância de empilhar) são comportamento - especificamente, comportamento da Pessoa P. Mas elas são duas coisas diferentes. Além disso, o princípio em si independe do conteúdo e referese a quaisquer e a todas as linhagens e suas respostas componentes, geradas por contingências entre respostas e consequências. O valor do princípio como uma generalidade científica depende da variedade do conteúdo que é adequado à fórmula e à variedade de organismos cujo comportamento pode ser previsto, alterado ou utilmente interpretado em termos do princípio.

A porção de 1 min de um fluxo comportamental representado na Figura 1 mostra uma situação estável que está presente quando todas as respostas ocorrem, e mostra certo tipo de mudança ambiental seguindo-se a algumas das respostas. Mudar a situação para S2 durante o próximo minuto e assegurar que nenhuma resposta seja seguida por $\mathrm{C} 1$ na Situação $\mathrm{S} 2$ pode adicionar um nível de complexidade. Digamos que na Situação S2, a superfície sobre a qual os blocos repousam não seja plana. Alternações entre $\mathrm{S} 1$ e $\mathrm{S} 2$ em intervalos variáveis, com $\mathrm{C} 1$ ocorrendo após R1 apenas em $\mathrm{S} 1$, tipicamente resulta em alta frequência de $\mathrm{R} 1$ em $\mathrm{S} 1$ e em baixa frequência de $\mathrm{R} 1$ em S2. A relação entre S1-R1-C1 é então especificada como uma contingência de três termos. Nesse caso, as características da contingência de três termos são "em superfícies planas (mas não em superfícies inclinadas), colocar blocos uns exatamente em cima dos outros resulta em torres."

Em um retrato mais dinâmico e completo de um fluxo comportamental, elementos da situação geralmente mudariam de momento a momento e a maioria das respostas seria seguida por algum tipo de mudança de estímulo (cf. Ray, Upson \& Henderson, 1977). A interação resultante entre mudanças ambientais e mudanças momento-a-momento em um fluxo comportamental é identificada como o comportamento da Pessoa P. ${ }^{4}$

As ações que recorrem em linhagens operantes mudam ao longo do tempo à medida que as contingências de seleção se desenvolvem e mudam. Uma maneira pela qual linhagens operantes mudam é 
quando as ações que as compõem se tornam mais complexas. Por exemplo, uma criança pode aprender a ligar aparelhos elétricos em tomadas, girar discos como o do timer da cozinha e passar a ferro lenços de bolso quando seu pai termina de passar a ferro sua camisa. Em uma situação demandando uma camisa passada a ferro, variações das três respostas podem ocorrer em uma nova sequência, resultando em uma camisa passada. Essa junção de respostas de linhagens operantes aprendidas em diferentes momentos tem sido denominada de adução de contingência (Layng \& Andronis, 1984). A relação entre a nova (aduzida) sequência de respostas e a consequência ambiental pode aumentar a probabilidade de repetições da sequência, eventualmente resultando em uma nova linhagem operante no repertório da criança. Chamemos de passar a ferro. A linhagem de passar a ferro é uma sequência recorrente de ações, cada instância da sequência sendo composta por elementos recrutados originalmente de linhagens operantes previamente adquiridas. Como todos os componentes da sequência são exigidos em cada ocorrência para produzir a consequência, a sequência de componentes adquire uma integridade funcional própria. $\mathrm{O}$ aninhamento ou a junção de ocorrências de uma linhagem em ocorrências mais complexas de outra linhagem é uma característica altamente consistente do comportamento humano. Um exemplo desse tipo de aninhamento é mostrado na Figura 2. Note que a linhagem é sempre composta por eventos recorrentes, e que a complexidade crescente é vista no número crescente de componentes nas ocorrências das linhagens hierárquicas.

\begin{tabular}{|l|l|l|}
\hline \multirow{5}{*}{ Pessoa A } & $\begin{array}{l}\text { Linhagens Operantes } \\
\text { (Atos operantes recorrentes) }\end{array}$ & Elementos de Cada Ocorrência \\
\cline { 2 - 3 } & Apertar <Entra> & $\begin{array}{l}\text { Colocar dedo na tecla } \\
\text { Pressionar a tecla }\end{array}$ \\
\cline { 2 - 3 } & Abrir MS Word & $\begin{array}{l}\text { Localizar ícone do programa na área } \\
\text { de trabalho } \\
\text { Colocar cursor sobre o ícone } \\
\text { Apertar <Entra> }\end{array}$ \\
\cline { 2 - 3 } & $\begin{array}{l}\text { Copiar texto de email para um } \\
\text { documento do Word }\end{array}$ & $\begin{array}{l}\text { Abrir MS Word } \\
\text { Abrir email } \\
\text { Selecionar texto a ser copiado } \\
\text { Clicar no ícone "copiar" } \\
\text { Alternar para página no documento do } \\
\text { Word } \\
\text { Clicar no ícone "colar" }\end{array}$ \\
\hline
\end{tabular}

Figura 2. Os componentes de ocorrências de linhagens anteriores integram-se com os componentes de ocorrências de linhagens posteriores em ocorrências mais complexas.

\section{CONTEÚDO AMBIENTAL EM CONTINGÊNCIAS OPERANTES}

A única característica necessária dos eventos ambientais em contingências de três termos é que eles sejam eventos empíricos. Para propósitos cotidianos, as pessoas têm considerado útil categorizar os eventos empíricos de diversos modos: visuais ou auditivos, temporalmente estendidos ou pontuais, verbais ou não verbais, sociais ou não sociais, e assim por diante. Cada evento singular pode ser categorizado de diferentes maneiras. Um relâmpago como um evento ambiental para alguém é visual, pontual, não verbal e não social. No ambiente de uma criança, meu assobiar uma canção pode ser categorizado como auditivo, estendido, não verbal e social. Outro modo pelo qual eventos empíricos podem ser categorizados é em termos da sua relação temporal com o comportamento de alguém que aprende ou de um sujeito que executa uma ação. O relâmpago pode ser uma situação (antecedente) na qual o comportamento de perguntar "relâmpago?" resulta na consequência "sim". Meu assobiar pode ser a situação na qual o assobiar da criança resulta no som de um dueto (consequência). Se o "sim" ou o som do dueto funcionam como o $\mathrm{C} 1$ da Figura 1 é uma questão empírica. Se eles funcionarem, os consideraremos como pertencentes a ainda outra categoria: reforçadores.

O ambiente social é definido, para os presentes propósitos, como o comportamento de outras pessoas que se relaciona ao comportamento de alguém que aprende ou executa uma ação. A pergunta "Qual o seu nome?" é parte do meu ambiente social. Eu responder meu nome é um evento social no ambiente de quem perguntou. Em qualquer ocorrência particular de uma resposta operante, a situação pode envolver eventos sociais e não sociais. Uma ou mais consequências também podem ser sociais ou não sociais. A Figura 3 fornece exemplos de contingências de três termos nas quais várias combinações de eventos sociais e não sociais podem funcionar como situação e consequência reforçadora em contingências operantes. Eventos ambientais estão em itálico e eventos sociais em negrito. 


\begin{tabular}{|l|l|l|}
\hline Situação & Resposta & Consequência \\
\hline Máquina de refrigerante & Colocar moedas & Bebida gelada \\
\hline Cinco xícaras na mesa & "Uma-duas-três-quatro-cinco & Professora acena com a \\
& xícaras" & cabeça e sorri \\
\hline Amigo diz "Vire à esquerda" & Virar à esquerda & Chegar ao destino \\
\hline Amigo pergunta "Que horas são?" & "Seis e quinze" & Amigo diz "Obrigado" \\
\hline
\end{tabular}

Figura 3. Eventos antecedentes (situação) e consequentes podem ser não sociais (em itálico) ou sociais (em itálico negrito), ou uma combinação de social e não social para respostas em uma linhagem operante.

A distinção cotidiana entre eventos sociais e não sociais tem encorajado alguns autores a distinguir entre "aprendizagem social" e "aprendizagem individual", sugerindo que elas envolvem processos de aprendizagem distintos (e.g., Box, 1984). Mas tal sugestão não é justificada, pois confunde processo e conteúdo. Toda aprendizagem é aprendizagem individual (Galef, 1988); ou seja, o lócus da aprendizagem envolve eventos no fluxo comportamental de um organismo individual que se relacionam com eventos ambientais. O caráter social de alguns ou de todos os eventos ambientais em contingências comportamentais distingue o conteúdo ambiental, não o processo pelo qual o ambiente afeta $o$ comportamento. Os processos comportamentais são os mesmos, quer o ambiente que funciona para selecionar o comportamento seja social ou não, e estes processos são um fato biológico.

O conteúdo social nas contingências que embasam a maior parte da aprendizagem dos humanos é uma característica definidora das culturas humanas. Embora culturas rudimentares possam ser vistas em outras espécies (Bonner, 1980; Harris, 1989), apenas os humanos dependem quase completamente da transmissão cultural de conteúdos comportamentais para a sobrevivência de sua espécie. Como a seleção natural pôde perder tanto controle direto sobre a sobrevivência de uma de suas criações? E quais características humanas geneticamente transmitidas afrouxaram o controle da seleção natural de modo tão dramático?

\section{HERANÇA BIOLÓGICA E CULTURA}

Além de uma combinação distintiva de características anatômicas e fisiológicas - tais como polegares opositores, locomoção bípede, visão e audição apuradas, alta plasticidade cerebral e um aparelho vocal intricado e flexível - a espécie humana tem diversas características comportamentais transmitidas geneticamente que parecem ter sustentado a emergência da cultura. A primeira característica comportamental que tornou possível as culturas humanas é sua sociabilidade a forte tendência das pessoas de passar a maior parte do tempo bem próximos uns dos outros. Sem essa tendência, haveria pouca possibilidade dos eventos sociais (i.e., o comportamento de membros da mesma espécie) servirem como eventos ambientais que adquirem função para o comportamento humano.

Skinner (1984b) identificou duas outras características comportamentais que juntas constituem o que pode ser chamado, um pouco vagamente, de "potencial de aprendizagem." Em primeiro lugar, as pessoas nascem com um repertório de "comportamento indiferenciado," que os distinguem de espécies sociais como as formigas, cujas interações específicas entre comportamento e ambiente são altamente restringidas pela hereditariedade. Enquanto as formigas, por exemplo, herdam padrões comportamentais específicos em resposta a eventos sociais específicos, o comportamento humano se relaciona a qualquer um de uma ampla variedade de eventos ambientais, dependendo das particularidades do ambiente social e não social no qual se viva. Para ser exato, a ação humana é restringida pela biologia humana; mas a cada geração as pessoas têm que aprender novamente tudo que seus ancestrais aprenderam - um processo realmente trabalhoso, mas o qual permite que o comportamento de cada geração se torne adaptado aos eventos ambientais presentes. E esses eventos ambientais podem mudar de geração para geração e isso tem sido feito em um ritmo cada vez mais acelerado.

Ao equipar as pessoas com um repertório comportamental largamente não comprometido, a seleção natural deu à nossa espécie muita liberdade para a adaptação comportamental local. Mas o repertório não comprometido das pessoas seria letal sem a segunda característica do potencial humano para a aprendizagem - a suscetibilidade do comportamento humano à seleção operante. Embora essa característica comportamental seja compartilhada por muitas espécies, as pessoas parecem ser excepcionalmente sensíveis a contingências comportamentais de seleção (Schwartz, 1974). Essa característica não depende de se os eventos ambientais em contingências de seleção comportamental são sociais ou não, mas a preponderância de eventos sociais nas contingências comportamentais praticamente garante a emergência de fenômenos culturais. 


\section{A EMERGÊNCIA DE FENÔMENOS CULTURAIS}

A combinação nos humanos de potencial para a aprendizagem e sociabilidade preparou o palco para a emergência da cultura - um novo tipo de fenômeno. Como a palavra comportamento, cultura é um substantivo incontável, uma palavra que se refere a uma categoria e também aos membros particulares dessa categoria (culturas específicas). Como uma categoria de fenômenos, definiremos cultura aqui como "padrões de comportamento aprendido transmitidos socialmente, bem como os produtos desse comportamento (objetos, tecnologias, organizações etc.)."

A cultura começa com a transmissão de conteúdo comportamental, aprendido por um organismo durante sua vida, para os repertórios de outros organismos. O lócus dos fenômenos culturais, portanto, é supraorganísmico. Ao contrário da aprendizagem, que se localiza nas relações temporais repetidas entre as ações de um único organismo e outros eventos empíricos, o lócus da cultura é supraorganísmico, pois envolve a repetição do comportamento inter-relacionado de dois ou mais organismos; o comportamento de um organismo funciona como a situação ou consequências nas contingências operantes que envolvem o comportamento do outro. Tal transmissão não requer nenhuma nova característica biológica ou processo comportamental, mas dá início a um novo tipo de linhagem: uma linhagem culturocomportamental (Glenn, 2003).

Linhagens culturo-comportamentais estendem-se profundamente na história humana, e também ocorrem em formas rudimentares em espécies não humanas (Kawamura, 1959). Um fato curioso sobre as culturas humanas é que após os humanos anatomicamente modernos terem passado dezenas de milhares de anos em culturas rudimentares, as culturas humanas tornaram-se bastante complexas em pouco mais de 10.000 anos - um período extraordinariamente curto em termos evolutivos (Harris, 1989). Isso sugere que muito antes da explosão cultural os humanos já possuíam as características anatômicas, fisiológicas e comportamentais (delineadas anteriormente) necessárias para a emergência e evolução de culturas complexas. Faltavam as mudanças nos eventos ambientais (sociais e materiais) que pudessem participar de contingências operantes ao longo de gerações, favorecendo comportamento individual que diferisse de geração para geração.

\section{Práticas culturais e macrocontingências}

Muito do conteúdo comportamental dos repertórios individuais humanos é similar ao conteúdo de muitos outros humanos. O termo práticas culturais referese a padrões similares de conteúdo comportamental, normalmente como resultado de similaridades nos ambientes. O termo metacomportamento tem sido sugerido para identificar a classe de comportamentos que constitui uma prática cultural (Mawhinney, 1995). Reconhecemos a necessidade de um termo que dê conta de uma classe supraorganísmica de comportamentos, mas usaremos o termo macrocomportamento aqui, pois ele é consistente com o restante da terminologia deste texto.
As práticas culturais podem ou não serem importantes para a sobrevivência de uma cultura. Um exemplo de uma prática que provavelmente não é crítica para a sobrevivência cultural é o fazer penteados. Muitos cabeleireiros podem fazer penteados de modo semelhante e essa semelhança de conteúdo comportamental constitui uma prática cultural. O que é importante assinalar é que essa semelhança não implica que a prática seja uma unidade cultural funcional. Em outras palavras, o comportamento dos vários cabeleireiros não é necessariamente relacionado funcionalmente ao comportamento de outros cabeleireiros. Cabeleireiros individuais podem simplesmente aprender ao longo do tempo a realizar certos tipos de penteado de certos modos como resultado do "visual" produzido e da aprovação dos seus chefes. Os produtos resultantes (penteados) consequentemente serão parecidos. Nem os penteados, nem o comportamento dos cabeleireiros são funcionalmente relacionados uns aos outros, apesar do comportamento de cada cabeleireiro ser inter-relacionado ao comportamento de seus respectivos chefes. Nesse caso, o comportamento semelhante de muitos indivíduos constitui uma prática cultural, mas não há evidências de transmissão cultural e, portanto, não há linhagem culturocomportamental.

Por outro lado, pode haver um ponto de transmissão cultural que ligue o comportamento de dois ou mais cabeleireiros. Por exemplo, o cabeleireiro A pode demonstrar a outros cabeleireiros uma forma de realizar penteados, e os outros podem reproduzir essa forma sob o olhar atento do criador e posteriormente com seus próprios chefes. Se um cabelo penteado por A é exibido em uma revista ou visto nos clientes por outros cabeleireiros, alguns deles podem ser capazes de produzir um resultado similar para seus próprios chefes. Esses casos envolvem transmissão cultural. Qualquer prática cultural pode ser composta por comportamentos gerados independentemente e também por comportamentos transmitidos socialmente. O ponto principal desses dois exemplos é que similaridade no conteúdo comportamental de muitos indivíduos é suficiente para se considerar o comportamento agregado uma prática cultural, mas não é suficiente para assumir transmissão cultural, e é ainda menos suficiente para assumir uma origem comum.

Outro modo de se distinguir práticas culturais é em termos da complexidade do conteúdo comportamental que constitui a prática. $\mathrm{O}$ macrocomportamento que constitui uma prática cultural específica pode envolver operantes facilmente identificáveis tais como fumar cigarros; ou padrões de comportamento compostos por vários operantes tais como fazer um penteado no cabelo, dirigir até o trabalho ou reciclar; ou padrões muito complexos de comportamentos entrelaçados de vários indivíduos, tais como os envolvidos na fabricação de automóveis. Envolvendo elementos simples ou complexos, todas as práticas culturais possuem duas características importantes para a presente discussão. A primeira é que envolvem muitas pessoas engajadas nas mesmas ações repetidas (comportando-se individualmente ou umas em relação às outras) e a segunda é que tais ações têm 
consequências - geralmente diversas consequências diferentes.

Considere o comportamento de dirigir até o trabalho. Uma consequência essencial para sua contínua repetição no fluxo comportamental de um indivíduo é chegar ao trabalho. Mas, na maioria dos casos, há outros comportamentos que resultariam na chegada ao trabalho (e.g., ir de carona, de transporte público, de bicicleta ou caminhando). $\mathrm{O}$ fato de que a maioria das pessoas dirige até o trabalho ao invés de ir até lá de outro modo sugere que consequências adicionais estão envolvidas e que elas diferem para os diferentes comportamentos. A Figura 4 apresenta algumas consequências prováveis de dirigir até o trabalho versus ir de carona.

\begin{tabular}{|l|l|l|l|}
\hline Comportamento & $\begin{array}{l}\text { Consequências que } \\
\text { Provavelmente Aumentam } \\
\text { a Frequência }\end{array}$ & $\begin{array}{l}\text { Consequências que } \\
\text { Provavelmente Diminuem } \\
\text { a Frequência }\end{array}$ & $\begin{array}{l}\text { Contribuição para 0 } \\
\text { Efeito Cumulativo }\end{array}$ \\
\hline $\begin{array}{l}\text { Dirigir até o } \\
\text { trabalho }\end{array}$ & $\begin{array}{l}\text { Mais conveniente } \\
\text { Toma menos tempo }\end{array}$ & Maior custo & Mais poluição \\
\hline $\begin{array}{l}\text { Ir de carona até 0 } \\
\text { trabalho }\end{array}$ & Menor custo & Menos conveniente & Menos poluição \\
\hline
\end{tabular}

Figura 4. Efeitos do comportamento que podem funcionar como consequências comportamentais estão em itálico e aqueles que não podem funcionar como consequências comportamentais estão em negrito; não há contingência entre o operante e o efeito cumulativo.

Note que todas as consequências que aparecem em itálico dependem apenas do comportamento do trabalhador individual e são experienciadas pouco tempo após o comportamento ocorrer. Apesar do trabalhador não controlar o custo da gasolina, ele tem controle sobre se mais ou menos do seu salário será gasto com gasolina e se ele levará mais ou menos tempo, com mais ou menos conveniência, para chegar ao trabalho. Por conta da correlação entre comportamento e essas consequências, essas últimas têm algum potencial para aumentar ou diminuir as probabilidades relativas de dirigir ou ir de carona. Quando múltiplas consequências têm funções conflitantes, o efeito global das consequências pode ser a soma algébrica de seus efeitos individuais (ver Skinner, 1953, pp. 218-223). E o efeito de cada uma dessas consequências é relativo. Por exemplo, se um trabalhador que dirigia para o trabalho foi transferido para um local de trabalho muito mais distante de casa, a mudança no valor relativo do preço da gasolina versus conveniência pode tornar a ida de carona mais provável que antes, especialmente porque o tempo envolvido em ir de carona versus dirigindo pode não diferir muito para o percurso mais longo.

O efeito do comportamento do nosso trabalhador na poluição do ar, mostrado em negrito na Figura 4, é um tipo muito diferente de consequência. Não é apenas uma questão da consequência ser muito pequena, muito atrasada ou muito cumulativa para que possa ter uma função comportamental, apesar de tudo isso ser verdadeiro e importante (ver R. W. Malott \& Suarez, 2004). Há algo mais que separa o efeito na poluição do ar dos outros efeitos dos dois comportamentos. A saber, mesmo se, por alguma mágica, fôssemos capazes de atribuir uma função poderosa a essa consequência, essa própria consequência poderia ser anulada pelo comportamento de outras pessoas. Nosso trabalhador, altamente motivado a ter um ar mais limpo, pode ir de carona pelos próximos 20 ou 30 anos, mas se muitas outras pessoas não fizerem o mesmo, o ar não ficará nem um pouco mais limpo. Em outras palavras, o ar mais limpo simplesmente não está sob controle do nosso trabalhador. Isso é, como Hardin (1968) sucintamente colocou a questão, a tragédia do bem comum. Não importa o quanto alguém aja para o bem comum, o comportamento dos outros pode anular tudo. Essa é a diferença crítica entre as consequências em itálico e as em negrito listadas na Figura 4.

Ulman (1998, p. 209) sugeriu o termo macrocontingência para definir "um conjunto de ações (topografias) diferentes de indivíduos diferentes sob controle consequente comum." O termo e a definição sugerem a extensão da definição padrão de um operante $\mathrm{e}$ poderiam ser analisados de dois modos. Macrocontingências poderiam referir-se à existência de atributos comuns em relações comportamentoconsequência entre vários indivíduos, ou ao controle exercido pelo efeito cumulativo de todas as topografias sobre as próprias topografias. Ulman deixa claro que o "controle consequente comum" são os efeitos cumulativos daquelas diferentes ações. Como mencionado anteriormente, contudo, os efeitos cumulativos não podem estar em uma relação contingente com o comportamento de qualquer indivíduo; eles, portanto, não podem controlar (como o fazem consequências operantes) o comportamento de indivíduos. E embora possa existir uma relação contingente entre a soma das topografias e o efeito cumulativo, as topografias somadas não são parte de 
uma linhagem que possa permanecer ou desaparecer como um todo como função da consequência. Se a consequência tem algum efeito sobre quaisquer linhagens operantes de pessoas individuais, esse efeito é independente de qualquer efeito que ela possa ter sobre linhagens operantes de outras pessoas. ${ }^{5}$

Isto posto, a noção de algum tipo de relação que é mais ampla do que as contingências operantes parece útil. Definirei uma macrocontingência, portanto, como a relação entre uma prática cultural e a soma agregada das consequências do macrocomportamento que constitui a prática. A Figura 5 mostra as relações em uma macrocontingência tal como definida aqui. $\mathrm{O}$ comportamento recorrente de cada pessoa tem seus próprios efeitos, e a relação entre o comportamento e esses efeitos pode alterar a probabilidade da recorrência do comportamento do indivíduo (como na Figura 1). Por exemplo, se o comportamento for dirigir até o trabalho, então o operante dirigir ao trabalho de cada pessoa é uma função da contingência entre dirigir para o trabalho e as consequências operantes desse comportamento. Além dessas consequências individuais, o comportamento combinado de todas as pessoas (o macrocomportamento) tem um efeito cumulativo. Esse efeito não pode funcionar como uma consequência comportamental já que não é contingente ao comportamento de nenhum motorista individual. Ele é contingente ao macrocomportamento da prática cultural.

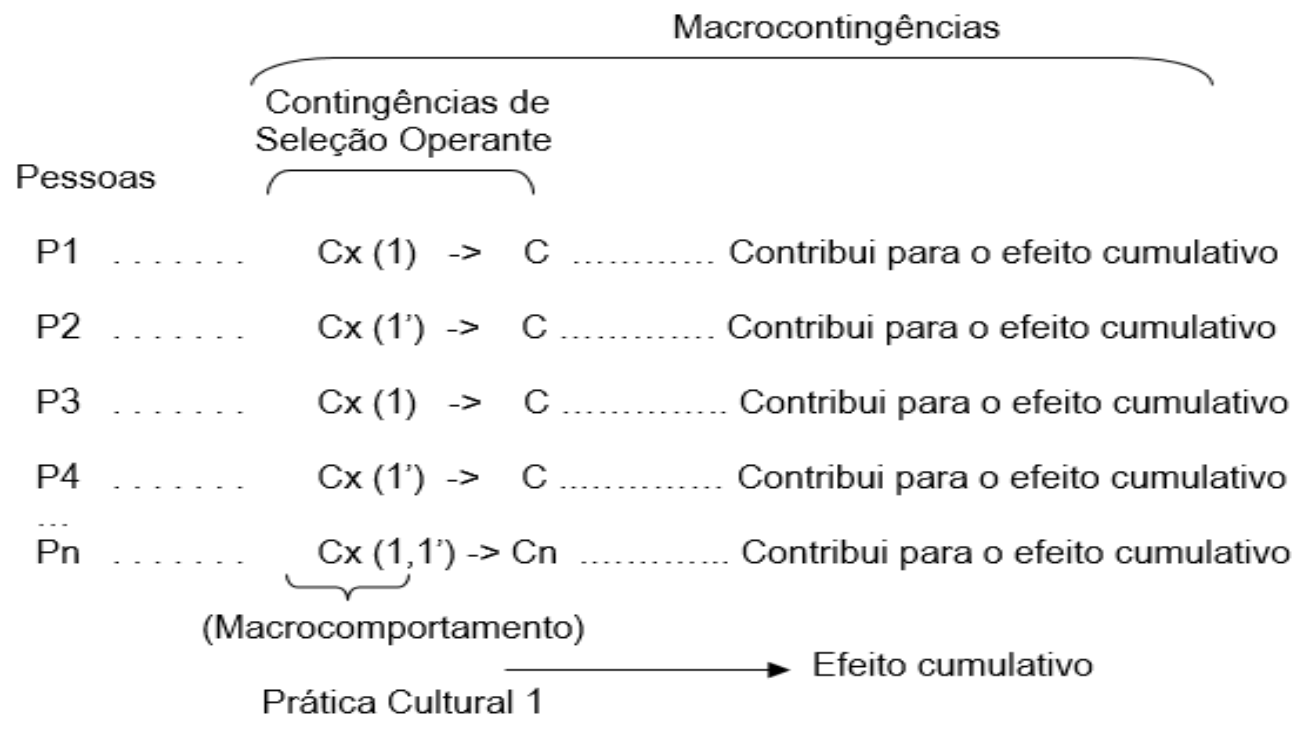

Figura 5. Operantes temporalmente não relacionados de diferentes pessoas (macrocomportamento) produzindo consequências comportamentais e também contribuindo para um efeito cumulativo.

Uma característica importante das macrocontingências é que seus efeitos cumulativos são aditivos. Quanto mais difundida a prática, maiores serão seus efeitos cumulativos; quanto maiores os efeitos cumulativos, mais importantes eles serão para o bem estar de um grande número de pessoas. Cada pessoa contribui para o efeito cumulativo de modo diretamente proporcional à frequência de seu comportamento. É o efeito cumulativo do comportamento em uma prática cultural que constitui um problema para as pessoas de uma cultura. Para continuar com o exemplo, o dirigir de cada indivíduo é como é devido aos efeitos relativos das suas múltiplas consequências comportamentais: chegar ao trabalho rapidamente, com muita facilidade e pouco dinheiro gasto com gasolina. Essas consequências que mantêm o comportamento de dirigir contribuem para a probabilidade de dirigir, mas não são os efeitos cumulativos: consumo de gasolina e os efeitos ambientais associados. Ademais, o comportamento não é um problema para os indivíduos que se comportam - ao contrário, é uma solução, embora não ideal, para o problema colocado pela distância do trabalho. Como no caso do comportamento de indivíduos, as práticas culturais também têm múltiplas consequências. Por exemplo, dois efeitos do comportamento de consumir são que ele ajuda a criar empregos e contribui para a degradação do ambiente físico. Tais efeitos incompatíveis das práticas culturais são ainda mais difíceis de reconciliar do que efeitos similarmente incompatíveis no comportamento individual. Isso se dá porque os múltiplos efeitos cumulativos de uma prática cultural tendem a ser mais vantajosos para algumas pessoas e mais desvantajosos para outras. No caso do comportamento individual, os custos e benefícios ao menos afetam a mesma pessoa.

As discussões sobre macrocontingências têm se centrado no efeito cumulativo de muitas pessoas "fazendo a mesma coisa" (permitindo uma ampla gama de topografias). As pessoas poderiam estar agindo individualmente (e.g., fumando) ou seus comportamentos poderiam estar inter-relacionados (e.g., ir de carona). De qualquer maneira, é a similaridade no conteúdo operante de muitas pessoas que permite chamarmos isso de uma prática cultural. Cada ocorrência do comportamento aumenta o efeito cumulativo. De tal modo que o efeito 
cumulativo depende do número de vezes que o ato ocorre, e esse número é função do número de pessoas engajadas no ato e da frequência do comportamento de cada pessoa.

A relação entre qualquer prática cultural específica e seus efeitos cumulativos pode ser criticamente importante para o bem-estar das pessoas da cultura e mesmo para a sobrevivência dessa cultura. Mas a prática cultural (como definida aqui e como em geral, ainda que vagamente, entendida) não pode participar em um processo de seleção. Isto ocorre pois a prática cultural é uma classe de atos que são funcionalmente independentes uns dos outros. Em outras palavras, recorrências dos atos não participam de uma linhagem. Elas são classificadas como "similares" em termos da sua forma e de seus efeitos, mas os membros da classe não são necessariamente relacionados por descendência, o que é uma característica definidora da evolução por seleção (Hull, Langman, \& Glenn, 2001). Em suma, a prática cultural não evolui como resultado de seleção cultural, mas como resultado de contingências comportamentais de seleção operando no comportamento de vários indivíduos; como resultado, uma prática cultural diferente passa a existir. Por exemplo, a prática cultural de fumar em prédios públicos tem sido substituída em muitos locais por uma prática de sair dos prédios públicos para fumar. A mudança na prática cultural é uma mudança comportamental de muitos indivíduos, cada um respondendo em função de seu próprio ambiente social. Quando há mudança nas práticas que constituem uma cultura, a mudança é um efeito colateral emergente de mudanças concorrentes em linhagens comportamentais de muitos indivíduos. O mecanismo causal é a seleção comportamental (i.e., o princípio do reforço).

Se certas práticas culturais humanas, ou seus efeitos cumulativos ameaçam a segurança mundial, então salvar o mundo exigirá necessariamente alterar as contingências operantes que mantêm linhagens comportamentais que contribuem para aqueles resultados. Tal ação requer a interpretação de fenômenos complexos por meio da linguagem da análise experimental do comportamento (ver Palmer, 1991). Como Skinner (1987) sugeriu, será difícil realizar mudanças culturais enquanto as práticas verbais das culturas não incluírem a linguagem da análise experimental do comportamento. Pelo lado positivo, quando essa linguagem guiar ações planejadas para mudar macrocomportamentos, essas ações poderão ser bastante bem sucedidas.

E quanto à sugestão de Skinner (1987) de que a análise experimental do comportamento embasaria uma teoria da evolução cultural da mesma forma que a teoria da evolução biológica de Darwin é embasada pela ciência experimental da genética? Essa sugestão precisa ser bem esclarecida porque as relações entre os genes e a espécie que os carrega são extremamente complexas, como o são os campos científicos da biologia evolutiva e da genética experimental. Talvez mais importante para a presente discussão seja a crescente complexidade (tanto da estrutura e função dos organismos quanto das relações ecológicas entre eles) característica da evolução dos fenômenos orgânicos. Culturas humanas parecem também terem sido caracterizadas por funções e estruturas organizacionais que têm se tornado cada vez mais complexas ao longo da história humana. O conceito de metacontingências pode nos ajudar a entender como tal complexidade evoluiu.

\section{METACONTINGÊNCIAS}

Uma clara distinção entre os conceitos de metacontingências e macrocontingências é necessária, pois artigos anteriores introduzindo o conceito de metacontingências (Glenn, 1986, 1988) combinaram terminologias adequadas à discussão de macrocontingências (como aqui definidas) e metacontingências (como aqui definidas). $O$ prefixo meta- junto com a raiz contingências pretende sugerir contingências de seleção que se relacionam hierarquicamente com, e incluem, contingências comportamentais. Elas representam "um tipo diferente de seleção," apesar de "nenhum processo comportamental novo" estar envolvido (Skinner, 1984a, p. 504). Metacontingências não são uma classe de comportamento alargada ou contingências comportamentais mais difundidas; no lugar disso, são o mecanismo de um tipo diferente de seleção. As metacontingências de seleção cultural emergiram apenas após os eventos sociais tornarem-se prevalentes no ambiente comportamental de uma espécie que possui a combinação humana de traços físicos e comportamentais.

O conceito de metacontingências aborda evolução por seleção quando as linhagens que evoluem não são os atos recorrentes de indivíduos (como esquematizado na Figura 1), mas sim contingências comportamentais entrelaçadas (CCEs) recorrentes que funcionam como uma unidade integrada e resultam em um produto que afeta a probabilidade de recorrências futuras dessas CCEs. A Figura 6 é um esquema de como metacontingências de seleção cultural acontecem ao longo do tempo. As CCEs recorrentes envolvem contingências operantes nas quais comportamento de duas ou mais pessoas funciona como evento ambiental para o comportamento de outras. Os produtos resultantes das CCEs recorrentes não são o efeito cumulativo dos participantes agindo individualmente, mas o efeito dos seus comportamentos inter-relacionados. Por exemplo, Marta e Todd frequentemente cozinham juntos. Marta prepara entradas, molhos e saladas com Todd servindo como ajudante, e Todd prepara aperitivos e sobremesas com Marta como ajudante. A coordenação temporal de cada uma de suas atividades baseia-se na observação do que o outro está fazendo durante toda a preparação da refeição. O produto do comportamento inter-relacionado é uma refeição com diversos pratos perfeitamente preparados apresentados no momento perfeito. A refeição não poderia ser produzida por Todd e Marta trabalhando em cozinhas separadas e combinando resultados de seus comportamentos individuais. Portanto, ela não é o efeito cumulativo dos comportamentos individuais. Ela é o produto do comportamento inter-relacionado. 
Tempo Estendido

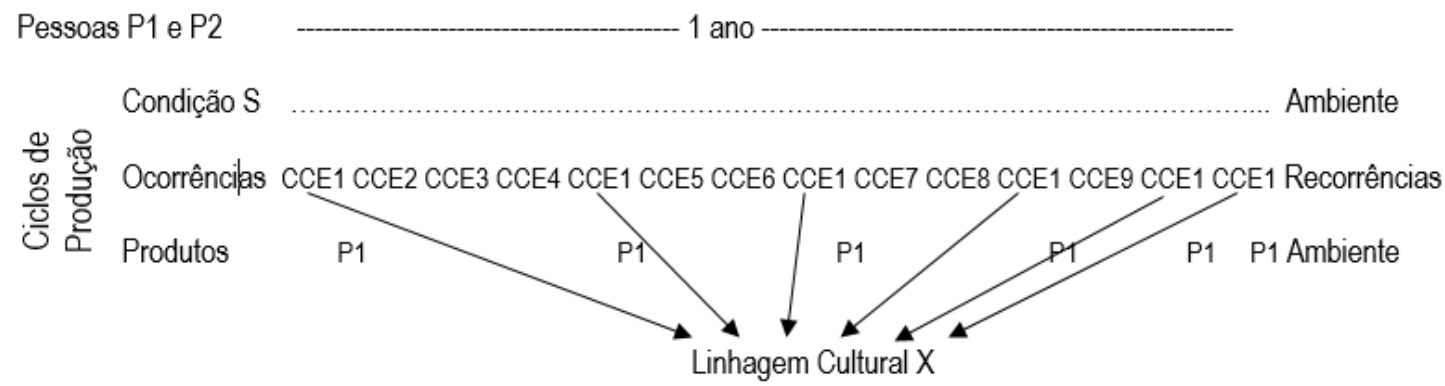

Figura 6. Recorrências de CCE1 ocorrendo com frequência crescente como resultado da metacontingência.

Metacontingências, portanto, são as contingências de seleção cultural. Elas dão origem ao acervo organizado de contingências comportamentais que constituem entidades de nível cultural de complexidade crescente. Continuemos com o exemplo da relação entre as CCEs de Todd e Marta e as refeições resultantes. Variações nas características das CCEs resultarão em variações no produto, e se a diferença nos produtos perpetuar alguns padrões de CCEs mais do que outros, seleção de nível cultural terá ocorrido. Note que o comportamento de Todd é função de contingências comportamentais que podem incluir o sabor das refeições preparadas, e que o comportamento de Marta é função de outras contingências comportamentais que podem incluir o sabor das refeições preparadas. Essas contingências comportamentais são necessárias para a continuidade e evolução dos operantes de Todd e Marta e, portanto, das CCEs; mas elas não são necessariamente suficientes para as CCEs. O produto das CCEs deve ser maior ou diferente que as refeições que Todd ou Marta poderiam gerar sozinhos para manter a recorrência das CCEs. É este "maior que" ou "diferente de" que é a fonte da evolução cultural que a distingue da evolução comportamental.

\section{COMPLEXIDADE CULTURAL}

A complexidade cultural é o produto da seleção cultural que resulta em hierarquias agrupadas de CCEs (Glenn \& Malott, 2004*). Por exemplo, Todd e Marta podem abrir um restaurante onde preparar refeições seja parte de um padrão maior de CCEs recorrentes. A Figura 7 mostra o agrupamento de relações de CCEs em linhagens culturais cada vez mais complexas. O padrão maior continuará a recorrer e evoluir a depender dos produtos do cozinhar, mas também dos produtos de outras CCEs na situação. $\mathrm{O}$ comportamento de outras pessoas pode se tornar parte do padrão maior e contribuir substancialmente para o produto que mantém as recorrências contínuas da CCE que constitui "o negócio". Finalmente, embora as CCEs precisem continuar recorrendo para a linhagem cultural continuar existindo, não é necessário que o comportamento de Todd ou

\footnotetext{
* Nota dos tradutores: O artigo de Glenn e Malott foi citado originalmente como "no prelo", no entanto, visto que o artigo já se encontra publicado, a tradução o cita com o ano de publicação (2004).
}

de Marta continuem participando. O comportamento de outros indivíduos pode substituir o de um ou de ambos, contanto que esse comportamento se ajuste suficientemente bem nas CCEs para gerar o produto. Talvez valha a pena ressaltar que a substituição do comportamento de um participante pelo comportamento de um outro em uma linhagem cultural quase sempre provoca ajustes nas CCEs e, portanto, sempre representa tanto oportunidades quanto ameaças à sobrevivência contínua da linhagem.

Assim como as respostas em contingências operantes, as CCEs em metacontingências podem gerar tanto produtos automáticos quanto produtos mediados socialmente que dependem das características do produto automático. Por exemplo, no início, as CCEs de Todd e Marta geravam produtos automáticos - refeições - que perpetuavam diferencialmente algumas variações das CCEs. Por fim, as CCEs constituindo o restaurante deles foram mantidas pelo comportamento de fazer pedidos dos clientes. Como no caso dos reforçadores sociais para o comportamento individual, a relação socialmente mediada entre as CCEs do restaurante e os recursos mantenedores gerados pelo consumo dos clientes fornece a base para relações mais complexas.

As metacontingências aninhadas de seleção cultural são a base para a evolução da complexidade cultural assim como para a manutenção (sobrevivência) de linhagens organizacionais em evolução. Da mesma forma que componentes de uma linhagem operante são incorporados em linhagens operantes com componentes mais complexos (como na Figura 2), componentes de uma linhagem de CCEs podem ser incorporados nas CCEs de maior complexidade (como na Figura 7). Essas entidades culturais mais complexas são as unidades em evolução individualmente identificáveis conhecidas como organizações: companhias individuais, suas corporações matrizes, escolas, distritos escolares, universidades, departamentos de universidades, agências governamentais e assim por diante. Cada uma dessas unidades existe enquanto consistirem em CCEs que gerem um produto que possa aumentar a chance da recorrência das CCEs. Todas elas são entidades que podem mudar ou evoluir ao longo do tempo ou podem desaparecer como um todo. Elas próprias não são práticas culturais, porque cada organização é uma entidade - uma linhagem de CCEs em evolução. 


\begin{tabular}{|l|l|l|}
\hline Organismos & $\begin{array}{l}\text { Linhagens Culturais } \\
\text { (Contingências } \\
\text { Comportamentais } \\
\text { Entrelaçadas Recorrentes) }\end{array}$ & Alguns Elementos de Cada Ocorrência \\
\hline Todd \& Marta & Preparam refeições & $\begin{array}{l}\text { Muitos comportamentos de cada pessoa } \\
\text { com função para os comportamentos de } \\
\text { outros }\end{array}$ \\
\hline $\begin{array}{l}\text { Todd, Marta, } \\
2 \text { garçons, } \\
1 \text { contador }\end{array}$ & Mantêm um restaurante & Preparam refeições \\
\hline $\begin{array}{l}\text { Todd, Marta, } \\
\text { muitos garçons, } \\
\text { contadores, } \\
\text { outros funcionários }\end{array}$ & $\begin{array}{l}\text { Comandam uma rede de } \\
\text { franquias }\end{array}$ & Merenciantes o fluxo de caixa \\
\hline
\end{tabular}

Figura 7. Os componentes de ocorrências de CCEs anteriores integram-se com os componentes de ocorrências de CCEs posteriores em ocorrências mais complexas.

Antes de prosseguir para como projetar mudanças culturais, revisemos a similaridade nas relações que constituem contingências operantes e metacontingências. Se uma linhagem comportamental vai continuar ou não a existir e a evoluir depende das consequências automáticas ou socialmente mediadas que seguem as instâncias comportamentais recorrentes. Isso significa que a mudança comportamental requer que as consequências sejam variáveis; isto é, as consequências podem ocorrer ou não, ou podem ocorrer em diferentes quantidades ou após diferentes intervalos de tempo, dependendo das características das instâncias comportamentais produtoras das mudanças ambientais. Um evento antecedente, endógeno ou exógeno ao organismo que se comporta, pode afetar uma dada ocorrência, mas recorrências são uma função das consequências. Portanto, o comportamento muda o ambiente e as mudanças resultantes podem, por sua vez, alterar a probabilidade futura desse tipo de comportamento. Dito de outro modo, instâncias comportamentais causam mudanças ambientais, e relações sistemáticas entre comportamento e consequências retroagem no sistema em curso causando mudanças na frequência e nas características de instâncias futuras (i.e., continuação e adaptação da linhagem).

A relação entre CCEs e seus produtos tem paralelos funcionais com as complexas relações das contingências comportamentais. As CCEs geram produtos, variações nas instâncias das CCEs levam a produtos diferenciais e a frequência futura das CCEs assim como suas características são uma função das relações diferenciais entre instâncias e produtos. Mudanças endógenas ou exógenas às CCEs podem resultar em uma variação que gere um produto diferente, e esse produto pode aumentar ou diminuir a probabilidade de recorrências das CCEs.

\section{PROJETANDO MUDANÇAS}

Pessoas têm se engajado em engenharia comportamental desde que começaram a funcionar como ambiente nas contingências operantes que davam suporte ao comportamento de outros. Apenas no século XX da presente era, contudo, a compreensão científica passou a ser empregada nessas práticas de engenharia. A engenharia cultural ainda não encontrou um firme embasamento científico. Um primeiro passo necessário é compreender os fenômenos nos quais se pretende intervir. A presente perspectiva permite a intervenção em dois tipos de fenômenos: macrocomportamento e metacontingências.

$\mathrm{O}$ macrocomportamento em práticas culturais pode ser identificado como problemático apenas quando seus efeitos cumulativos são reconhecidos e geralmente muito tempo é necessário para se entender os diversos efeitos de práticas culturais específicas. O único modo de se fazer algo com relação aos efeitos cumulativos de macrocomportamentos é encontrar formas para se alterar o comportamento do maior número possível de indivíduos participantes. Por exemplo, quanto mais indivíduos derem carona ou utilizarem o transporte público para irem ao trabalho ao invés de dirigirem sozinhos, maior será a melhoria da qualidade do ar (ou mais lentamente a qualidade do ar piorará). Quando o número de participantes em uma prática é grande, uma mudança no comportamento de uma pequena porcentagem deles pode resultar em uma diferença importante. Se $10 \%$ dos motoristas dos EUA dessem carona para duas outras pessoas, poder-se-ia produzir uma redução significativa na poluição do ar. O que poderia levar a uma mudança no comportamento de $10 \%$ dos motoristas? Considerando que o comportamento de cada motorista é função das contingências operantes presentes, devemos considerar as consequências do comportamento de dirigir para o trabalho versus as consequências de ir de carona, como discutido anteriormente e ilustrado na Figura 4. Para os 
propósitos da nossa discussão, assumimos que os efeitos dos comportamentos listados na Figura 4 poderiam funcionar como consequências comportamentais, com exceção do efeito na poluição do ar.

Atualmente, as tentativas da sociedade de engendrar macrocomportamentos alternativos são realizadas com pouca compreensão dos potenciais efeitos cumulativos (Nevin, 1998) e pouca atenção é dispensada às muitas contingências operantes que possivelmente mantêm o comportamento operante dos indivíduos participantes na prática atual. Como o macrocomportamento em práticas culturais é função de contingências operantes que operam independentemente, mas de modo similar e concorrentemente sobre o comportamento de muitas pessoas, analistas do comportamento têm corretamente chamado a atenção para a análise das contingências que mantêm o comportamento constituinte da prática. Mattaini (1995), em particular, tem argumentado que os analistas do comportamento deveriam ser treinados especificamente para focar nos comportamentos com efeitos cumulativos que afetam a viabilidade da cultura. Quando intervenções são planejadas para alterar o efeito cumulativo de uma prática cultural, elas devem necessariamente identificar as contingências operantes que dão suporte ao comportamento dos indivíduos participantes da prática. Quanto mais indivíduos tiverem seus comportamentos modificados, maior será o impacto sobre o efeito cumulativo. Esse método de intervenção cultural implica modificar as contingências operantes que possam manter o comportamento de muitas pessoas. Biglan (1995) descreveu muitos dos comportamentos em práticas culturais americanas modernas que resultam em efeitos cumulativos indesejados e identificou muitas das contingências comportamentais mediadas socialmente que mantêm esses comportamentos. Outros autores (e.g., Goldstein \& Pennypacker, 1998; R. W. Malott, 1998) propuseram interpretações de diversos macrocomportamentos específicos e sugestões de intervenção. Sob a orientação editorial de Richard Rakos, Janet Ellis e Mark Mattaini, o periódico Behavior and Social Issues tem dedicado diversos números à análise de macrocomportamentos com efeitos cumulativos altamente destrutivos.

Como muito do comportamento operante das pessoas é parte integrante de organizações que têm CCEs recorrentes, a sobrevivência dessas organizações é, no mínimo, importante para essas pessoas. O simples fato dessas organizações existirem, contudo, sugere que suas CCEs foram selecionadas pelo ambiente externo e, portanto, são uma parte importante da cultura mais ampla, quer estruturas organizacionais alternativas sejam consideradas mais desejáveis ou não. As intervenções, dessa forma, também podem voltar-se para as CCEs em metacontingências.

CCEs podem ser alteradas de dois modos, análogos aos dois modos pelos quais características das espécies podem ser alteradas. O primeiro modo é alterar o ambiente selecionador externo e aguardar que variações nas CCEs gerem produtos adequados às novas contingências de seleção. Isso equivale a alterar as contingências selecionadoras e esperar que as coisas se arranjem. O segundo modo é semelhante a descobrir e alterar as características genéticas que ameaçam a existência de uma espécie dado o ambiente selecionador presente. Esta tática envolve alterar os componentes das CCEs de modo que eles sejam mais adequados ao ambiente selecionador presente. Variações planejadas das CCEs recorrentes podem ser projetadas para gerar produtos mais adequados às demandas do ambiente externo.

Projetar mudanças para melhorar a sobrevivência de organizações (arranjos recorrentes de CCEs) requer analisar tanto as metacontingências vigentes quanto as contingências comportamentais específicas que afetam o produto das CCEs. É óbvio que não se pode analisar todas as CCEs e contingências operantes de organizações complexas. Deve haver um modo de se distinguir entre aquelas que podem ser ignoradas e aquelas que devem ser abordadas. M. E. Malott (2003) descreveu uma abordagem à mudança organizacional que combina um modelo comportamental de engenharia de sistemas com análise de metacontingências. As colaborações dela com funcionários de organizações empresariais e com pelo menos uma instituição de educação superior (M. E. Malott \& Salas-Martinez, 2004) demonstram a importância - de fato, a necessidade - de se isolar as CCEs que não atendem às contingências de seleção e então identificar o comportamento operante que deve ser alterado para gerar o tipo de mudanças nas CCEs exigido pelo ambiente externo.

Em suma, para realizar mudanças nas CCEs organizadas que funcionam como unidades culturais em evolução é necessário identificar as CCEs contribuindo para um produto e a função do produto em manter (ou não) recorrências da CCE. Variações nas CCEs podem ser produzidas manipulando sistematicamente as contingências comportamentais que as compõem e essas variações podem aumentar ou diminuir a probabilidade da geração de produtos com função mantenedora.

\section{A RELAÇÃO DAS METACONTINGÊNCIAS COM CONTINGÊNCIAS OPERANTES E MACROCONTINGÊNCIAS}

Metacontingências, assim como contingências comportamentais, envolvem dois tipos de causalidade, como pode ser visto comparando-se as Figuras 1 e 3 . Primeiro, as recorrências de CCEs geram produtos (análogos às consequências produzidas por recorrências de respostas operantes). Segundo, os produtos afetam a frequência e outras medidas das recorrências futuras dessas CCEs. As contingências de seleção em metacontingências estão entre as unidades do nível cultural (CCEs) e os seus ambientes selecionadores. Unidades culturais em evolução são ciclos recorrentes de CCEs. Como operantes em um repertório, as entidades recorrentes podem tornar-se partes de entidades cada vez mais complexas que formam uma linhagem própria (vide Figura 7). Os produtos gerados por um ciclo de CCEs podem afetar futuros ciclos de CCEs, da mesma forma que 
as consequências de uma ocorrência comportamental podem afetar ocorrências futuras desse comportamento. Se estivermos interessados em alterar as recorrências de CCEs, podemos fazê-lo alterando os componentes das CCEs para melhor atender às exigências de seleção presentes ou alterando o ambiente selecionador. A primeira estratégia seria comparável à alteração genética e a última, à seleção artificial.

As CCEs em metacontingências, assim como o comportamento individual em contingências operantes, recorrem em linhagens que evoluem e que mudam como função do seu ambiente selecionador. Eles também se assemelham em sua relação com macrocontingências. Do mesmo modo que comportamentos operantes similares de muitas pessoas podem contribuir para um efeito cumulativo, as CCEs de muitas organizações diferentes também podem contribuir para um efeito cumulativo, como mostrado na Figura 8. As linhagens comportamentais de diferentes pessoas que participam de uma prática cultural evoluem independentemente, como o fazem as linhagens de CCEs de diferentes organizações. Porém, tanto os comportamentos quanto as CCEs também podem contribuir para efeitos cumulativos que não participam diretamente da seleção, mas que, contudo, podem ser indicadores importantes da viabilidade da cultura.

\section{Macrocontingências}

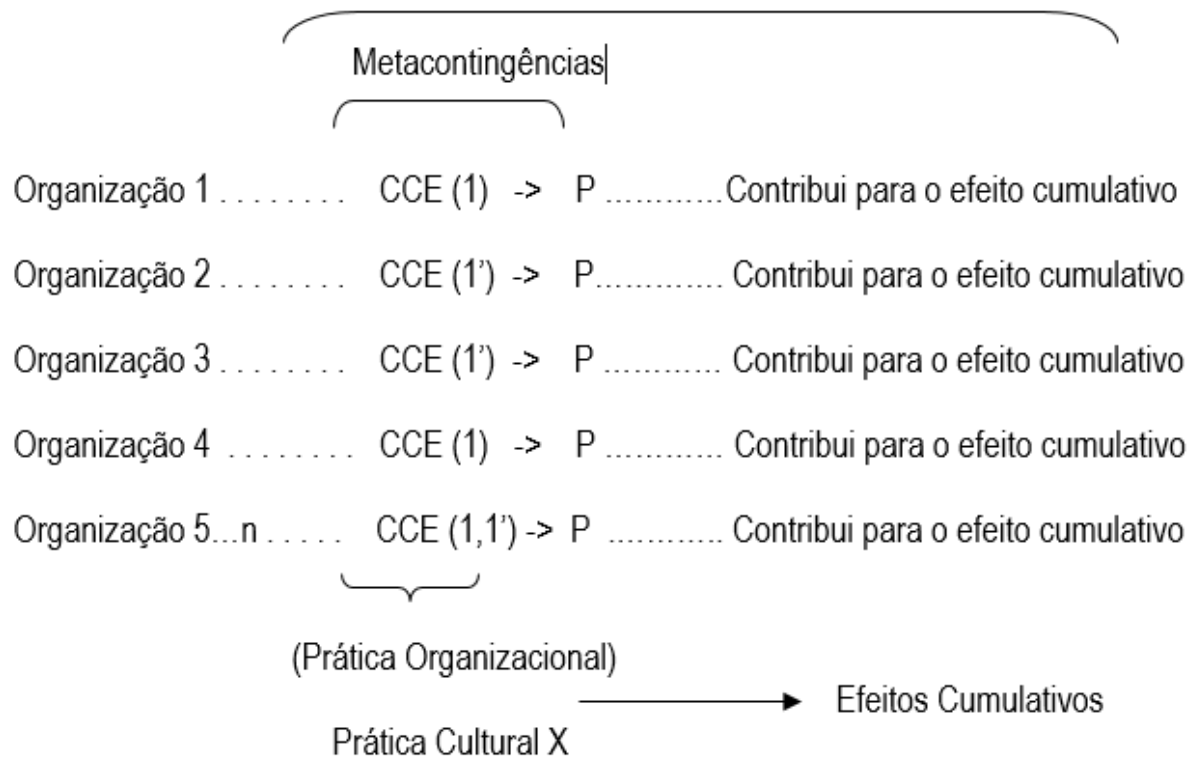

Figura 8. CCEs temporalmente não relacionadas de diferentes organizações (práticas organizacionais), produzindo consequências comportamentais e também contribuindo para um efeito cumulativo.

As organizações na Figura 8 poderiam ser programas de pós-graduação envolvendo CCEs que geram estudantes treinados como analistas do comportamento. Cada programa gera estudantes formados (entre outras coisas) cujas performances contribuem direta e indiretamente para a seleção das CCEs recorrentes que geram turma após turma de estudantes formados. As CCEs que geram pós-graduados em análise do comportamento constituem uma prática cultural e têm efeitos cumulativos, incluindo o número de pessoas preparadas para cargos acadêmicos, o número de indivíduos que podem ser atendidos por analistas do comportamento profissionais, a quantidade de financiamento federal que provavelmente será liberado para pesquisadores analistas do comportamento, entre outros. Apesar dos analistas do comportamento individuais e dos professores de programas individuais poderem resolver agir com base em dados sobre os efeitos cumulativos do comportamento agregado ou das CCEs agregadas, esses efeitos não podem selecionar nenhuma das linhagens operantes individuais ou das linhagens de CCEs individuais, pois não há linhagens de entidades recorrentes que produzam esses efeitos. Se estivermos interessados na alteração dos efeitos cumulativos de uma prática cultural, devemos encontrar um modo de alterar as contingências comportamentais dos macrocomportamentos ou as metacontingências que mantém as CCEs da complexidade cultural organizada. Quanto mais contingências individuais ou metacontingências organizacionais forem alteradas, maior a mudança potencial no efeito cumulativo.

Quanto maior o número de organizações caracterizadas pelos mesmos tipos de CCEs, mais provavelmente consideraremos estes tipos de CCEs uma prática cultural. Afirmações como "as práticas culturais das empresas japonesas são diferentes das práticas culturais das empresas americanas" referem-se a semelhanças nas CCEs que caracterizam companhias americanas e semelhanças nas 
CCEs que caracterizam companhias japonesas, assim como a diferenças entre as companhias americanas e japonesas.

\section{CONCLUSÃO}

As distinções aqui traçadas entre contingências comportamentais, macrocontingências metacontingências representam uma tentativa de esclarecer a maneira complexa pela qual a seleção atua com respeito ao comportamento de pessoas e a organizações de CCEs nas quais muito do comportamento humano está envolvido. Práticas culturais per se não podem evoluir. Os membros constituintes das práticas evoluem, contudo, sejam eles os operantes de indivíduos ou as CCEs de entidades organizacionais com vida própria, acima e além do comportamento das pessoas particulares que participam delas.

Como culturas são construções humanas e sua complexidade crescente origina-se da complexidade crescente de entidades que participam em metacontingências, é muito provável que as pessoas possam alterar ao menos alguns elementos de suas próprias culturas. A não ser que compreendamos como as culturas surgem e evoluem, entretanto, será difícil fazer escolhas sensatas sobre o que pode ou deve ser modificado.

\section{REFERÊNCIAS}

Biglan, A. (1995). Changing cultural practices: A contextualist framework for intervention research. Reno, NV: Context Press.

Bonner, J.T. (1980). The evolution of culture in animals. Princeton, NJ: Princeton University Press.

Box, H.O. (1984). Primate behavior and social ecology. London: Chapman \& Hall.

Diamond, J. (1997). Guns, germs, and steel. New York: Norton.

Friman, P.C. (2004). Up with this I shall not put: 10 reasons why I disagree with Branch and Vollmer on behavior used as a count noun. The Behavior Analyst, 27, 99-106.

Galef, B.G., Jr. (1988). Imitation in animals: History, definition, and interpretation of data from the psychological laboratory. In T. R. Zentall \& B. G. Galef, Jr. (Eds.), Social learning: Psychological and biological perspectives (pp. 3-28). Hillsdale, NJ: Lawrence Erlbaum.

Glenn, S.S. (1986). Metacontingencies in Walden Two. Behavior Analysis and Social Action, 5, 2-8.

Glenn, S.S. (1988). Contingencies and metacontingencies: Toward a synthesis of behavior analysis and cultural materialism. The Behavior Analyst, 11, 161-179.

Glenn, S.S. (2003). Operant contingencies and the origin of cultures. In K.A. Lattal \& P.N. Chase (Eds.), Behavior theory and philosophy (223-242). New York: Klewer Academic/Plenum.

Glenn, S.S. \& Malott, M.E. (2004). Complexity and and selection: Implications for organizational change. Behavior and Social Issues, 13, 89-106.

Goldstein, M.K. \& Pennypacker, H.S. (1998). From candidate to criminal: The contingencies of corruption in elected public office. Behavior and Social Issues, 8 , $1-8$.

Hardin, G. (1968). The tragedy of the commons. Science, $162,1243-1248$.

Harris, M. (1989) Our kind. New York: Harper \& Row.

Hull, D. L., Langman, R. E. \& Glenn, S. S. (2001). A general account of selection: Biology, immunology, and behavior. Behavioral and Brain Sciences, 24, 511573.

Johnson, S. (2001). Emergence. New York: Simon \& Schuster.

Kawamura, S. (1959). The process of sub-culture propagation among Japanese macaques. Primates, 2, 43-60.

Layng, T.F.J. \& Andronis, P.T. (1984). Toward a functional analysis of delusional speech and hallucinatory behavior. The Behavior Analyst, 7, 139156.

Malott, M. E. (2003). Paradox of organizational change. Reno, NV: Context Press.

Malott, M. E., \& Salas-Martinez, M. W (2004) Strategic organizational change in higher education. $O B M$ Newsletter, 18 (2), 9-11.

Malott, R.W. (1998). Performance management and welfare reform: The three-contingency model of performance management applied to welfare reform. Behavior and Social Issues, 8, 109-139.

Malott, R.W \& Suarez, E.A.T. (2004). Principles of behavior. Upper Saddle River, NJ: Pearson Education.

Mattaini, M. (1995). Teaching cultural design: Shaping new behaviorists. Behavior and Social Issues, 5 (2), 21-28.

Mawhinney, V.T. (1995). Metabehaviors as discriminative stimuli for planned cultural evolution. Behavior and Social Issues, 5 (1), 35-44.

Nevin, J. A. (1998). Contingencies of welfare reform. Behavior and Social Issues, 8, 101-108.

Palmer, D. C. (1991). A behavioral interpretation of memory. Em L.J. Hayes \& P.N. Chase (Eds.), Dialogues on verbal behavior (pp. 261-279). Reno, NV: Context Press.

Ray, R.D., Upson, J.D. \& Henderson, B.J. (1977). A systems approach to behavior III: Organismic pace and complexity in time-space fields. Psychological Record, 27, 649-682.

Schwartz, B. (1974). On going back to nature: A review of Seligman and Hager's Biological Boundaries of Learning. Journal of the Experimental Analysis of Behavior, 21, 183-198.

Skinner, B. F. (1953). Science and human behavior. New York: Free Press.

Skinner, B.F. (1984a). Author's response: Some consequences of selection. Behavioral and Brain Sciences, 7, 502-509.

Skinner, B. F. (1984b). The evolution of behavior. Journal of the Experimental Analysis of Behavior, 41, 217-221.

Skinner, B.F. (1987). Why we are not acting to save the world. Em Upon further reflection (pp. 1-14). Englewood Cliffs NJ: Prentice-Hall. 
Todorov, J.C., Moreira, M.B., \& Moreira, M. (2004). Metacontingencies: Interlocked and unrelated contingencies. In Contemporary challenges in the behavioral approach: A Brazilian overview (pp. 221225). Santo André, Brasil: ESETec Editores Associados.

Ulman, J.D. (1998). Toward a more complete science of human behavior: Behaviorology plus institutional economics. Behavior and Social Issues, 8, 195-217.

\section{Notas:}

${ }^{1}$ A autora agradece imensamente a Leslie Burkett pelas suas várias leituras do manuscrito enquanto ele estava em preparação. Seus comentários críticos foram inestimáveis. Endereço para correspondência com a autora: Departament of Behavior Analysis, P.O. Box 310919, University of North Texas, Denton, Texas 76205 (email: sglenn@unt.edu).

2 Os parágrafos anteriores valem-se dos trabalhos de Bonner (1980), Harris (1989) e Diamond (1997).

${ }^{3}$ Esse exemplo é o mais simples possível e não deve sugerir que o princípio requeira respostas simples, que instâncias sejam instantâneas, que conjuntos ou sequências de respostas não possam ser selecionadas, e assim por diante. A função de S1 não é discutida pois o esquema não mostra controle diferencial sobre R1.

${ }^{4}$ Linhagens operantes específicas ou particulares (e suas ocorrências componentes) são em geral identificadas coloquialmente como comportamentos, implicitamente reconhecendo seu status ontológico como algo individualmente identificável. Por exemplo, "A criança engajou-se em dois comportamentos problema" pode significar que ela foi observada repetidamente batendo em outras meninas no almoço e também gritando quando o recreio acabava. Por outro lado, tudo que um ou todos os organismos fazem é designado como comportamento (um substantivo incontável). Friman (2004) defendeu eloquentemente ambos os usos em termos práticos. Aqui, sugere-se que os diferentes usos também respeitam uma distinção ontológica. Especificamente, o substantivo incontável refere-se a um tipo de fenômeno empírico (i.e., atividade) e o uso do plural sugere localização com respeito a uma pessoa específica.

5 Macrocontingências, como definidas aqui, podem envolver diferentes topografias de diferentes pessoas, os resultados agregados das quais são uma mudança no ambiente de muitas pessoas. Todorov, Moreira e Moreira (2004) fornecem exemplos de tais relações. Os resultados agregados das diferentes topografias nos exemplos deles, como no exemplo da poluição do ar aqui apresentado, não podem ter uma função seletiva sob estas topografias por causa da fraca correlação entre o comportamento de qualquer indivíduo e o resultado agregado. 